\title{
Perceived injustice moderates the relationship between pain and depressive symptoms among individuals with persistent musculoskeletal pain
}

\author{
Whitney Scott BA, Michael Sullivan PhD
}

W Scott, M Sullivan. Perceived injustice moderates the relationship between pain and depressive symptoms among individuals with persistent musculoskeletal pain. Pain Res Manage 2012;17(5):335-340.

BACKGROUND: Numerous investigations report that depressive symptoms frequently coexist with persistent pain. However, evidence suggests that symptoms of depression are not an inevitable consequence of pain. Diathesis-stress formulations suggest that psychological factors interact with the stress of pain to heighten the risk of depressive symptoms. Perceptions of injustice have recently emerged as a factor that may interact with the stress of pain to increase depressive symptoms.

OBJECTIVES: The purpose of the present study was to examine whether perceived injustice moderates the relationship between pain and depressive symptoms.

METHODS: A total of 107 individuals with persistent musculoskeletal pain completed self-report measures of pain severity, depressive symptoms, perceived injustice and catastrophizing.

RESULTS: A hierarchical regression analysis revealed that the interaction between pain severity and perceived injustice uniquely contributed an additional $6 \%$ of the variance to the prediction of depressive symptoms, beyond the main effects of these variables. Post hoc probing indicated that pain was significantly related to depressive symptoms at high, but not low levels of perceived injustice. This finding remained statistically significant even when controlling for pain catastrophizing.

CONCLUSIONS: The results suggest that perceived injustice augments the relationship between pain severity and depressive symptoms. The inclusion of techniques specifically targeting perceptions of injustice may enhance the effectiveness of interventions aimed at reducing symptoms of depression for individuals presenting with strong perceptions of injustice.

Key Words: Depressive symptoms; Musculoskeletal pain; Perceived injustice

$\mathrm{N}$ umerous investigations have reported that depressive symptoms frequently coexist with persistent pain. Recent epidemiological studies suggest that the coprevalence likely lies in the range of $20 \%$ to $25 \%(1,2)$. Thus, while symptoms of depression may be prevalent in individuals with pain conditions, they do not appear to be an inevitable consequence of pain.

Research has appealed primarily to 'diathesis-stress' formulations to explain how depressive symptoms might arise following the development of a pain condition $(3,4)$. Diathesis-stress formulations attempt to explain why some individuals experience significant symptoms of depression as a function of their pain experience while others do not. These models suggest that depressive symptoms arise when vulnerability factors (diatheses) interact with vulnerability-relevant contextual factors (stresses) (5). It has been suggested that any factor that increases the perceived threat value of pain or the burden of its concomitant losses might serve as a diathesis for symptoms of depression $(3,6)$.

Research has identified several psychological diatheses for depressive symptoms. There are indications that negative cognitions, such as catastrophizing, may contribute to the onset or maintenance of
La perception d'injustice modère le lien entre la douleur et les symptômes de dépression chez les patients souffrant de douleurs musculosquelettiques persistantes

HISTORIQUE : Selon de nombreuses explorations, les symptômes de dépression accompagnent souvent la douleur persistante. Cependant, des données probantes laissent supposer que les symptômes de dépression ne constituent pas une conséquence inévitable de la douleur. D'après les modèles diathèse-stress, des facteurs psychologiques s'ajoutent au stress de la douleur pour accroître le risque de symptômes de dépression. Les perceptions d'injustice ont récemment émergé comme facteur susceptible d'interagir avec le stress de la douleur pour accroître les symptômes de dépression. OBJECTIFS : La présente étude visait à examiner si la perception d'injustice modère le lien entre la douleur et les symptômes de dépression. MÉTHODOLOGIE : Au total, 107 personnes souffrant de douleurs musculosquelettiques persistantes ont fourni des mesures autodéclaréessur la gravité de la douleur, les symptômes de douleur, la perception d'injustice et la catastrophisation.

RÉSULTATS : Une analyse de régression hiérarchique a révélé que l'interaction entre la gravité de la douleur et la perception d'injustice contribuait à elle seule à $6 \%$ supplémentaires de la variation de prédiction des symptômes de dépression, au-delà des principaux effets de ces variables. Des sondages ultérieurs ont indiqué que la douleur était liée de manière significative aux symptômes de dépression lorsque le taux de perception d'injusticeétait élevé, mais pas lorsqu'il était faible. Cette observation demeure statistiquement significative même en présence d'un contrôle de catastrophisation de la douleur.

CONCLUSIONS : D'après les résultats, la perception d'injustice accroît le lien entre la gravité de la douleur et les symptômes de dépression. L'inclusion de techniques visant expressément les perceptions d'injustice peut accroître l'efficacité des interventions visant à réduire les symptômes de dépression chez les personnes ayant de fortes perceptions d'injustice.

depressive symptoms by augmenting the perceived threat of pain (7). There are also indications that individuals who have a propensity to make internal, stable and global attributions for negative outcomes might be at an increased risk of depressive symptoms (8). Other vulnerability factors that have been discussed in relation to depressive symptoms include perfectionistic traits, dependency and perceived lack of social support (9-11).

Perceived injustice has recently emerged as another factor that may play a role in the development and maintenance of mental health outcomes associated with pain. Perceptions of injustice are likely to arise in circumstances under which an individual has suffered undeserved hardship or irreparable loss (12-14). In the context of persistent pain, perceived injustice has been operationally defined as an appraisal cognition comprising elements of the exaggerated severity of loss consequent to injury or pain onset, perceived irreparability of loss, a sense of unfairness and blame (15).

Injustice-relevant constructs, such as unfairness and victimization, have been suggested to play a central role in the development of depressive symptoms $(16,17)$. Experiences of unfairness and victimization might impact depressive symptoms through derogating 
individuals' sense of self and violating their assumptive world views $(12,16)$. Findings suggest that the experience of victimization uniquely contributes to negativistic cognitive styles that increase vulnerability to depressive symptoms (18). Several studies have shown that perceptions of unfairness or injustice in nonpatient samples are associated with more severe depressive symptoms (19-22). It has been suggested that perceptions of injustice might augment the negative emotional impact of adverse events (23). Recent research suggests that perceived injustice may be associated with heightened levels of depressive symptoms among individuals with persistent musculoskeletal pain following injury $(15,24)$.

It is possible that cross-study variations in the magnitude of the relationship between pain and depression may be due to sample differences in perceived injustice. In other words, perceived injustice might augment the negative emotional impact of pain experience. Cross-study variations in perceived injustice might exaggerate the pain-depression relationship in some studies and obscure the relationship in others. Research has yet to examine the moderating role of perceived injustice on the relationship between pain and depressive symptoms.

The importance of research addressing the role of perceived injustice as a correlate of the pain-depression relationship is not restricted to theoretical concerns but also has implications for clinical practice. Cognitive-behavioural interventions are currently considered to be the psychological treatment of choice for depressive symptoms associated with pain $(25,26)$. However, perceptions of injustice have not been systematically addressed in interventions for depressive symptoms associated with pain $(27,28)$. Because depressive symptoms have been shown to contribute to the chronicity of pain conditions (29), the development of more effective intervention approaches to manage depressive symptoms may also impact positively on recovery from pain-eliciting injuries.

The purpose of the present study was to investigate the moderating role of perceived injustice on the pain-depression relationship. Individuals with persistent musculoskeletal pain completed questionnaires of pain severity, depressive symptoms, perceived injustice and pain catastrophizing. Analyses addressed whether high levels of perceived injustice augmented the relationship between pain and depressive symptoms. Because perceived injustice has been shown to be correlated with pain catastrophizing, analyses also addressed whether perceived injustice acted as a significant moderator of the pain-depression relationship while controlling for pain catastrophizing.

\section{METHODS}

\section{Participants}

Participants in the present study consisted of 107 individuals (63 women, 44 men) with persistent musculoskeletal pain. The mean duration of pain for the sample was 8.3 years (range three months to 31 years). The mean age of the sample was 41 years (range 20 to 60 years). Approximately one-half of the sample $(49 \%)$ was unemployed at the time of assessment. The majority of participants $(64 \%)$ were married or living in a common-law partnership. The majority of participants $(60 \%)$ had completed some level of postsecondary education.

\section{Procedure}

The present study was approved by the Ethics Review Committee of the Centre de recherche interdisciplinaire en réadaptation de Montréal métropolitain (CRIR). Individuals with persistent musculoskeletal pain were recruited through advertisements placed in newspapers and in rehabilitation clinics in Montreal, Quebec. All participants had undergone a medical evaluation to ascertain diagnosis. Participants were invited to sign a consent form as a condition of participating in the study. Participants were asked to provide demographic information, as well as to complete self-report questionnaires assessing cognitive and affective variables related to pain and distress.

\section{Self-report measures}

Participants had the option of completing either the French or English version of the measures described below. Ninety-four participants completed the measures in French and 13 individuals completed the measures in English.

\section{Pain severity}

Participants rated their present pain severity on an 11-point numerical rating scale, ranging from 0 (no pain) to 10 (excruciating pain).

\section{Depressive symptoms}

The Beck Depression Inventory II (BDI-II) (30) was used as a measure of depressive symptoms. On this scale, participants are asked to respond to 21 items describing cognitive, affective and somatic symptoms of depression. Values associated with the endorsed statements were summed to produce a total score, in which higher scores indicate more severe depressive symptoms. Both the English and French versions of the BDI-II have been shown to be reliable and valid measures of depressive symptoms $(30,31)$. The BDI-II has also been validated for use with chronic musculoskeletal pain patients (32).

\section{Perceived injustice}

The Injustice Experiences Questionnaire (IEQ) (15) was used to examine pain-related perceptions of injustice. Participants were asked to rate the frequency with which they experience each of 12 pain-related thoughts when considering their pain condition on a five-point scale ranging from 0 (never) to 4 (all the time). Research suggests that the IEQ yields two correlated factors, labelled severity/irreparability of loss and blame/unfairness. Examples of items loading onto the severity/irreparability of loss factor include, "Most people don't understand how severe my condition is", and "My life will never be the same". Examples of items loading onto the blame/ unfairness factor include, "I am suffering because of someone else's negligence", and "It all seems so unfair" (15). The IEQ has been shown to have high internal and test-retest reliability and to be valid for use among English- and French-speaking individuals with musculoskeletal pain $(15,24,33)$.

\section{Pain catastrophizing}

The Pain Catastrophizing Scale (PCS) (34) was used to measure painrelated catastrophic thinking. Participants were asked to indicate the frequency with which they experience 13 thoughts or feelings while they are in pain. Items were rated on a five-point scale, ranging from 0 (not at all) to 4 (all the time). The PCS measures three distinct components of catastrophizing: rumination, magnification and helplessness (34). Research indicates that both the English and French versions of the PCS have high internal consistency and are associated with increased pain and depressive symptoms $(34,35)$.

\section{Demographic variables}

Participants responded to questions regarding their age, sex, illness duration, marital status and level of education.

\section{Data analytic approach}

Previous findings indicate that the 'severity/irreparability of loss' and 'blame/unfairness' factors of the IEQ are highly correlated (15). Therefore, for the purpose of the present study, only participants' total IEQ scores were used in the analyses.

T-tests for independent samples were used to compare men and women on study variables. Correlations were computed to examine the associations among pain severity, depressive symptoms, perceived injustice and pain catastrophizing. A hierarchical regression analysis was conducted to examine the moderating effect of perceived injustice on the relationship between pain and depressive symptoms. Because previous research has shown that perceived injustice is correlated with pain catastrophizing (15), an additional regression analysis examined whether the moderating effect of injustice was significant even when controlling for pain catastrophizing. In both regression analyses, the tolerance and variance inflation factors of the independent variables fell within acceptable ranges (36). 


\section{RESULTS}

\section{Sample characteristics}

Means and SDs for participants' scores on pain severity, depressive symptoms, perceived injustice, and pain catastrophizing are presented in Table 1. Mean scores on these measures are comparable with those that have been reported in previous research on individuals with persistent musculoskeletal pain (15). Women reported significantly higher pain severity and depressive symptoms than men, $\mathrm{t}(105)=1.98$, $\mathrm{P}=0.05$, and $\mathrm{t}(105)=2.51, \mathrm{P}<0.05$, respectively. Men and women did not differ significantly with respect to perceived injustice and pain catastrophizing scores.

\section{Correlations among study variables}

Pearson product-moment correlations among the self-report variables are presented in Table 2. Consistent with previous research, pain severity was significantly correlated with pain catastrophizing and depressive symptoms (34). Also consistent with previous findings, perceived injustice, pain catastrophizing and depressive symptoms were significantly intercorrelated (15).

Perceived injustice as a moderator of the relationship between pain and depressive symptoms

Within a correlational framework, moderation occurs when a third variable affects the strength of the relationship between the independent and dependent variables. Moderation is supported when the interaction between the independent and moderator variables significantly predicts the dependent variable, controlling for the main effects of these variables in the regression equation (37).

A hierarchical regression analysis was conducted to examine whether perceived injustice augmented the relationship between pain and symptoms of depression (Table 3 ). Consistent with the recommendations of Cohen (38), the main effects of pain severity and perceived injustice were centred before the analysis, and the centred variables were used to compute the interaction term. Pain severity was entered in the first step of the analysis, and contributed significantly to the prediction of depressive symptoms, $F(1,105)=16.36$, $\mathrm{P}<0.001$. Perceived injustice was entered in the second step, and added significant variance to the prediction of depressive symptoms, $\mathrm{F}(1,104)=19.73, \mathrm{P}<0.001$. The pain severity-perceived injustice interaction term was entered in the final step, and contributed significant variance to the prediction of depressive symptoms, beyond the variance accounted for by pain severity and perceived injustice, $F(1,103)=9.91, P<0.01$. Examination of the beta weights from the final regression equation revealed that the main effects of pain severity, $\beta=0.31, \mathrm{t} \quad(106)=3.9, \mathrm{P}<0.001$, perceived injustice, $\beta=0.33$, $\mathrm{t}(106)=4.1, \mathrm{P}<0.001$, and their interaction, $\beta=0.26$, $\mathrm{t}(106)=3.2$, $\mathrm{P}<0.01$, each contributed significant unique variance to the prediction of depressive symptoms.

Post hoc probing was performed following the significant pain severity-perceived injustice interaction to obtain the simple slopes of pain severity for one standard deviation below $(-1 \mathrm{SD} ; \mathrm{M}=13.94)$ and above (+1 SD; $M=36.90)$ the mean on perceived injustice. Post hoc probing enables an examination of whether the simple slopes are significant and in the expected direction. Post hoc probing of the simple slopes indicated that pain severity was not significantly related to depressive symptoms for participants with low perceived injustice, $\beta=0.07, t(106)=0.6, P>0.05$. In contrast, pain severity was significantly associated with depressive symptoms among individuals with high perceived injustice, $\beta=0.56, \mathrm{t}(106)=4.9, \mathrm{P}<0.001$ (Figure 1).

The moderating effect of perceived injustice controlling for pain catastrophizing

An additional hierarchical regression analysis was conducted to examine the moderating role of perceived injustice after controlling for pain catastrophizing (Table 4). Pain catastrophizing was entered in the first step of the analysis, and significantly contributed to the prediction of depressive symptoms, $\mathrm{F}(1,105)=65.60, \mathrm{P}<0.001$. The
TABLE 1

Mean scores for study variables

\begin{tabular}{lccc}
\hline & Women $(\mathbf{n}=\mathbf{6 3})$ & Men $(\mathbf{n}=\mathbf{4 4})$ & $\mathbf{P}$ \\
\hline Age & $41.8 \pm 9.6$ & $39.6 \pm 8.5$ & $\mathrm{~ns}$ \\
Pain severity & $4.9 \pm 1.9$ & $4.1 \pm 2.2$ & 0.05 \\
BDI-II & $20.3 \pm 11.3$ & $14.6 \pm 11.9$ & $<0.05$ \\
IEQ & $26.8 \pm 11.6$ & $23.4 \pm 11.2$ & $\mathrm{~ns}$ \\
PCS & $27.9 \pm 11.9$ & $26.4 \pm 10.1$ & $\mathrm{~ns}$ \\
\hline
\end{tabular}

Data presented as mean $\pm S D$ unless otherwise indicated. BDI-II Beck Depression Inventory II; IEQ Injustice Experiences Questionnaire; ns Not significant; PCS Pain Catastrophizing Scale

TABLE 2

Correlations among study variables

\begin{tabular}{lrrrrr}
\hline & $\mathbf{1}$ & $\mathbf{2}$ & $\mathbf{3}$ & $\mathbf{4}$ & $\mathbf{5}$ \\
\hline 1. Age & & & & & \\
2. Pain duration* & 0.14 & & & & \\
3. Pain severity & 0.15 & -0.04 & & & \\
4. BDI-II & 0.02 & 0.02 & $0.37^{\dagger}$ & & \\
5. IEQ & 0.01 & 0.05 & 0.15 & $0.42^{\dagger}$ & \\
6. PCS & -0.05 & -0.15 & $0.42^{\dagger}$ & $0.62^{\dagger}$ & $0.55^{\dagger}$ \\
\hline
\end{tabular}

${ }^{*} n=94 ;{ }^{\dagger} P \leq 0.01$. BDI-II Beck Depression Inventory II; IEQ Injustice Experiences Questionnaire; PCS Pain Catastrophizing Scale.

TABLE 3

Regression analysis examining the moderating role of perceived injustice on the relationship between pain and depressive symptoms

\begin{tabular}{lcccc}
\hline DV: BDI-II & $\Delta \mathbf{R}^{\mathbf{2}}$ & Fchange & $\mathbf{P}$ & $\boldsymbol{\beta}$ \\
\hline Step 1, Pain severity & 0.14 & $16.4(1,105)$ & $<0.001$ & $0.31^{*}$ \\
Step 2, IEQ & 0.14 & $19.7(1,104)$ & $<0.001$ & $0.33^{*}$ \\
Step 3, Pain severity $\times$ IEQ & 0.06 & $9.9(1,103)$ & $<0.01$ & $0.26^{*}$ \\
\hline
\end{tabular}

${ }^{*} P \leq 0.01$ BDI-II Beck Depression Inventory II; IEQ Injustice Experiences Questionnaire; PCS Pain Catastrophizing Scale.

main effects of pain severity and perceived injustice were entered in the second and third steps, but did not add significant variance to the prediction of depressive symptoms, beyond that of pain catastrophizing, $\mathrm{F}(1,104)=2.34, \mathrm{P}>0.05$ and $\mathrm{F}(1,103)=2.15, \mathrm{P}>0.05$. The pain severity-perceived injustice interaction term was entered in the final step, and contributed significant unique variance to the prediction of depressive symptoms, above and beyond the variance accounted for by pain catastrophizing, pain severity and perceived injustice, $F(1,102)=8.15, P<0.01$. Examination of the beta weights from the final regression equation revealed that pain catastrophizing, $\beta=0.45$, $\mathrm{t}(106)=4.7, \mathrm{P}<0.001$, and the interaction between pain severity and perceived injustice, $\beta=0.21$, $t(106)=2.9, P<0.01$, contributed significant unique variance to the prediction of depressive symptoms.

\section{DISCUSSION}

The present study adds to emerging research examining the role of perceived injustice in adjustment to chronic pain. The present study supports previous findings showing significant correlations between perceived injustice, pain catastrophizing and depressive symptoms (15). The results of the present study extend previous findings in showing that perceived injustice moderates the relationship between pain severity and depressive symptoms.

The current findings suggest that pain severity was significantly associated with depressive symptoms at high, but not low, levels of perceived injustice. In previous research, the magnitude of correlations between pain and symptoms of depression has ranged from $r=0.01$ to $r=0.50(39-41)$. The present results suggest that cross-study differences in participants' levels of perceived injustice may account for some of this variability. In study samples in which participants have high levels of perceived injustice, the relationship between pain and 


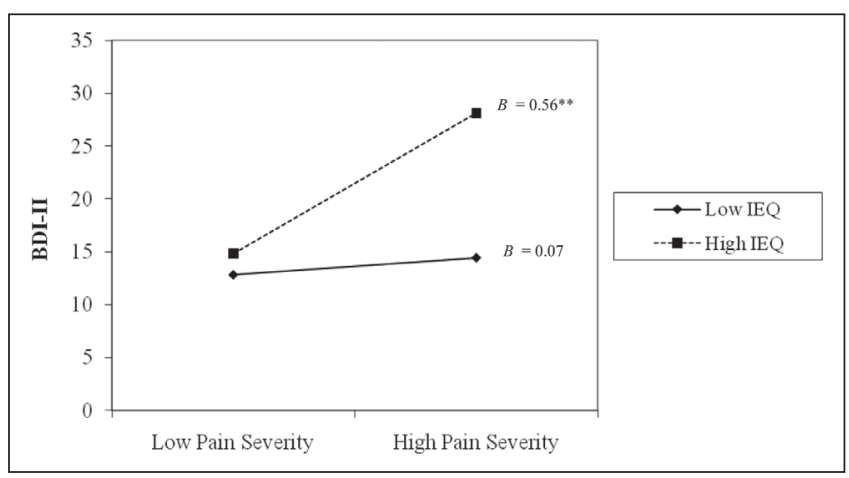

Figure 1) Post hoc probing of simple slopes for the interaction between pain severity and perceived injustice in predicting depressive symptoms. Low IEQ, $n=23$; high IEQ, $n=25$; **P $\leq 0.01$. BDI-II Beck Depression Inventory II; IEQ Injustice Experiences Questionnaire.

\section{TABLE 4}

Regression analysis examining the moderating role of perceived injustice, controlling for the effect of pain catastrophizing

\begin{tabular}{lccll}
\hline & $\Delta \mathbf{R}^{\mathbf{2}}$ & Fchange & \multicolumn{1}{c}{$\mathbf{P}$} & \multicolumn{1}{c}{$\boldsymbol{\beta}$} \\
\hline DV: BDI-II & & & & \\
Step 1, PCS & 0.39 & $65.6(1,105)$ & $<0.001$ & $0.45^{*}$ \\
Step 2, Pain severity & 0.01 & $2.3(1,104)$ & $>0.05$ & 0.16 \\
Step 3, IEQ & 0.01 & $2.2(1,103)$ & $>0.05$ & 0.12 \\
Step 4, Pain & 0.04 & $8.2(1,102)$ & $<0.01$ & $0.21^{*}$ \\
$\quad$ severity $\times$ IEQ & & & &
\end{tabular}

${ }^{*} P \leq 0.01$. BDI-II Beck Depression Inventory-II; IEQ Injustice Experiences Questionnaire; PCS Pain Catastrophizing Scale.

depressive symptoms might be augmented, while it might be reduced in samples in which participants have low levels of perceived injustice

Proceeding from a diathesis-stress framework, perceived injustice might interact with the stress of pain in several ways to heighten depressive symptoms. For example, numerous empirical and theoretical reports have highlighted the central role of loss in the precipitation and maintenance of depressive symptoms (42-44). Appraisals of the severity and irreparability of loss have been discussed as central elements of the perception of injustice $(15,45)$. The irreparability of loss might also reflect an attributional style toward negative events (ie, stable, global) that is characteristic of hopelessness or helplessness cognitions, both of which have been associated with depressive symptoms (46-48). Attempts to derive meaning from injustice might also induce social comparison processes that negatively impact individuals' sense of self. For example, individuals might construe their suffering as the result of personal weakness, deviance or unworthiness of health, compared with others who are pain-free (16). In turn, negativistic selfother comparisons might contribute to depressive symptoms $(49,50)$.

Although perceived injustice and pain catastrophizing were strongly correlated in the present study, concepts of blame and unfairness have not been discussed in theoretical frameworks of catastrophizing (51). There are several plausible explanations for the observed association. Catastrophizing might be a precursor to perceiving injustice, such that individuals might first need to appraise pain catastrophically before viewing it as irreparable. Catastrophizing has been shown to be a strong determinant of pain-related losses, including losses of employment and function (52). Such loss experiences have been discussed as central to the perception of injustice (45). Research also suggests that high catastrophizing individuals might be more likely to experience punitive responses from others (53). In turn, punitive or invalidating responses from others might enhance the perception of being treated unfairly.

While perceived injustice and catastrophizing appear to overlap to a degree, the current finding that the injustice-pain severity interaction predicted depressive symptoms controlling for catastrophizing supports the partial distinctiveness of these constructs. A number of processes that are theoretically unrelated to pain catastrophizing may account for the unique impact of perceived injustice on depressive symptoms. For example, perceptions of injustice entail blame cognitions. Research suggests that blame attributions are likely to incite revenge motives $(54,55)$. Revenge motives might contribute to confrontational interactions with insurance representatives, health professionals or family members. Confrontational relationships might be associated with increased stress and reduced quality of support, both of which have been associated with depressive symptoms (56-59).

The finding of a nonsignificant association between perceived injustice and pain severity in the present study is consistent with previous research suggesting that perceived injustice is more strongly related to indexes of disability than pain experience $(15,33)$. As discussed, the losses engendered by pain, including loss of function, independence and financial security, might be particularly likely to impact injustice perceptions. In the absence of significant loss, pain severity might not be sufficient to incite perceptions of injustice. Beyond the distributive injustice of pain-related losses, individuals might also perceive procedural injustice, which concerns unfairness in the methods, mechanisms and processes of determining outcomes (14). Irrespective of the degree of pain severity, procedures related to the adjudication of compensation claims, medical treatment decisions, and employment reintegration might be viewed as unfair among individuals with persistent pain conditions $(60,61)$.

Anger has been discussed as a common emotional reaction to perceived injustice and there is a large body of literature linking anger to adverse pain-related outcomes, including depressive symptoms $(12,62,63)$. The 'self-silencing' effect of anger suppression might contribute to poor self-esteem and feelings of identity loss, thereby increasing depressive symptoms $(64,65)$. Reduced endogenous opioid analgesia associated with anger expression might also increase symptoms of depression through exacerbating pain sensitivity $(66,67)$. Future work is needed to specify the relationship among perceived injustice, anger and depressive symptoms.

Recent research has shown a buffering effect of just world beliefs on psychological distress among individuals with chronic pain (68). Presently, the relationship between perceived injustice, just world beliefs and depressive symptoms is not well understood. To the extent that pain-related injustice perceptions are discrepant with prepain just world beliefs, unsuccessful or self-damaging attempts to reduce one's cognitive dissonance might lead to psychological distress $(69,70)$. Research is needed to determine how these constructs influence one another to impact depressive symptoms and other affective responses, including demoralization and anxiety, among patients with persistent pain.

At present, the effective management of perceived injustice in the treatment of individuals with persistent musculoskeletal pain has not been systematically addressed. Cognitive reappraisal techniques for injustice perceptions have been described as potentially useful interventions for individuals with anger-related difficulties $(33,71)$. Acceptance-based interventions might help de-emphasize the focus on loss, unfairness and retribution (72,73). Existential and narrativefocused interventions may help reduce injustice perceptions by enabling individuals to create positive meaning from their suffering $(74,75)$. Future research is needed to determine the effectiveness of these interventions for pain patients presenting with high perceived injustice.

It is important to note that individuals' perceptions of injustice might not simply be mental constructions, but reflective of some degree of actual injustice (15). For example, patients might face legitimate and continuing inequities in access to services and resources in medical, insurance and employment systems. The recent focus in the pain literature on racial disparities in the receipt of pain treatment might be evidence of one such inequity (76). In such circumstances, optimal management of perceived injustice might require interventions addressing both individuals' appraisals of their life circumstance and actual systems-based inequities. 
Several limitations deserve consideration. The correlational design of the present study warrants caution in the interpretation of the direction of causality of the findings. For example, it is plausible that heightened depressive symptoms lead to greater perceptions of injustice. Evidence from one population-based, prospective study suggests that the perception of unfairness is an antecedent to poor mental health (77). However, future work is needed to determine the prospective nature of the relationship between perceived injustice and depressive symptoms among individuals with persistent pain. Another limitation was the use of a self-report measure of depressive symptoms instead of a structured clinical interview. Because high scores on self-report measures do not necessarily indicate the presence of a diagnosable depressive disorder, it is not clear whether the relationships observed in the present study would apply to individuals with a clinical diagnosis.

In spite of these limitations, the findings of the present study suggest that perceived injustice might augment the negative impact of pain on depressive symptoms among individuals with persistent musculoskeletal pain. Results indicated that the interaction between pain severity and perceived injustice significantly predicted depressive symptoms, independent of the effect of pain catastrophizing. Therefore, the interaction between pain severity and perceived injustice appears to have unique predictive utility. Techniques to specifically target perceived injustice might help reduce the depressive symptoms of patients presenting with strong injustice perceptions.

ACKNOWLEDGEMENTS: The authors thank Nicole Davidson and Beatrice Garfinkiel for their assistance in recruitment, testing and data entry.

FUNDING AND CONFLICTS OF INTEREST: This research was supported by funds from the Canadian Institutes for Health Research and the Fonds de la Recherche en Santé du Québec. The authors have no financial interests associated with the findings of this research.

\section{REFERENCES}

1. Currie SR, Wang J. Chronic back pain and major depression in the general Canadian population. Pain 2004;107:54-60.

2. McWilliams LA, Cox BJ, Enns MW. Mood and anxiety disorders associated with chronic pain: An examination in a nationally representative sample. Pain 2003;106:127-33.

3. Banks SM, Kerns RD. Explaining high rates of depression in chronic pain: A diathesis-stress framework. Psychol Bull 1996;119:95-110.

4. Dersh J, Polatin PB, Gatchel RJ. Chronic pain and psychopathology: Research findings and theoretical considerations. Psychosom Med 2002;64:773.

5. Monroe SM, Simons AD. Diathesis stress theories in the context of life stress research: Implications for the depressive disorders. Psychol Bull 1991;110:406-25.

6. Pincus T, Williams A. Models and measurements of depression in chronic pain. J Psychosom Res 1999;47:211-9.

7. Keefe FJ, Brown GK, Wallston KA, Caldwell DS. Coping with rheumatoid arthritis pain: Catastrophizing as a maladaptive strategy. Pain 1989;37:51-6.

8. Abramson LY, Seligman MEP, Teasdale JD. Learned helplessness in humans: Critique and reformulation. J Abnorm Psychol 1978;87:49-74.

9. Blatt SJ. The destructiveness of perfectionism: Implications for the treatment of depression. Am Psychol 1995;50:1003.

10. Nietzel MT, Harris MJ. Relationship of dependency and achievement/ autonomy to depression. Clin Psychol Rev 1990;10:279-97.

11. López-Martínez AE, Esteve-Zarazaga R, Ramírez-Maestre C. Perceived social support and coping responses are independent variables explaining pain adjustment among chronic pain patients. J Pain 2008;9:373-9.

12. Miller DT. Disrespect and the experience of injustice. Annu Rev Psychol 2001;52:527-53.

13. Lerner MJ. Justice motive - some hypotheses as to its origins and forms. J Pers 1977;45:3-52

14. Lind EA, Tyler TR. The social psychology of procedural justice. New York: Plenum Press, 1988:267
15. Sullivan MJL, Adams H, Horan S, Maher D, Boland D, Gross R. The role of perceived injustice in the experience of chronic pain and disability: Scale development and validation. J Occup Rehabil 2008;18:249-61.

16. Janoff Bulman R, Frieze IH. A theoretical perspective for understanding reactions to victimization. J Soc Issues 1983;39:1-17.

17. Sheppard M. Mental health and social justice: Gender, race and psychological consequences of unfairness. Br J Soc Work 2002;32:779.

18. Gibb BE, Abramson LY, Alloy LB. Emotional maltreatment from parents, verbal peer victimization, and cognitive vulnerability to depression. Cognitive Ther Res 2004;28:1-21.

19. Bezrukova K, Spell CS, Perry JL. Violent splits or healthy divides? Coping with injustice through faultlines. Pers Psychol 2010;63:719-51.

20. Kivimaki M, Vahtera J, Elovainio M, Virtanen M, Siegrist J. Effort-reward imbalance, procedural injustice and relational injustice as psychosocial predictors of health: Complementary or redundant models? Occup Environ Med 2007;64:659-65.

21. Lennon MC, Rosenfield S. Relative fairness and the division of housework: The importance of options. Am J Soc 1994:506-31.

22. Tepper BJ. Health consequences of organizational injustice: Tests of main and interactive effects. Organ Behav Hum Dec 2001;86:197-215.

23. Mikula G, Scherer KR, Athenstaedt $U$. The role of injustice in the elicitation of differential emotional reactions. Pers Soc Psychol Bull 1998;24:769-83.

24. Sullivan MJL, Thibault P, Simmonds MJ, Milioto M, Cantin AP, Velly AM. Pain, perceived injustice and the persistence of posttraumatic stress symptoms during the course of rehabilitation for whiplash injuries. Pain 2009;145:325-31.

25. Campbell LC, Clauw DJ, Keefe FJ. Persistent pain and depression: A biopsychosocial perspective. Biol Psychiat 2003;54:399-409.

26. Morley S, Eccleston C, Williams A. Systematic review and metaanalysis of randomized controlled trials of cognitive behaviour therapy and behaviour therapy for chronic pain in adults, excluding headache. Pain 1999;80:1-13.

27. McCracken LM. Contextual cognitive-behavioral therapy for chronic pain. Seattle: IASP Press, 2005.

28. Thorn BE. Cognitive therapy for chronic pain: A step-by-step guide. New York: The Guilford Press, 2004.

29. Bair MJ, Robinson RL, Katon W, Kroenke K. Depression and pain comorbidity: A literature review. Arch Intern Med 2003;163:2433-45.

30. Beck A, Steer R, Brown GK. Manual for the Beck Depression Inventory-II. San Antonio Psychological Corporation; 1996.

31. Beck A, Steer R, Brown G. BDI II, inventaire de dépression de Beck. Paris: ECPA, 1998.

32. Arnau RC, Meagher MW, Norris MP, Bramson R. Psychometric evaluation of the Beck Depression Inventory-II with primary care medical patients. Health Psychol 2001;20:112-9.

33. Sullivan MJL, Davidson N, Garfinkel B, Siriapaipant N, Scott W. Perceived injustice is associated with heightened pain behaviour and disability in individuals with whiplash injuries. Psychol Inj Law 2009;2:238-47

34. Sullivan MJL, Bishop SR, Pivik J. The Pain Catastrophizing Scale: Development and validation. Psychol Assess 1995;7:524-32.

35. French D, Noel M, Vigneau F, French J, Cyr C, Evans R. L'Echelle de dramatisation face a la douleur PCS-CF: Adaptation canadienne en langue francaise de l'echelle "Pain Catastrophizing Scale". Can J Behav Sci 2005;37:181-92.

36. Morrow-Howell N. The M-Word: Multicollinearity in multipleregression. Soc Work Res 1994;18:247-51.

37. Baron RM, Kenny DA. The moderator-mediator variable distinction in social psychological research: Conceptual, strategic, and statistical considerations. J Pers Soc Psychol 1986;51:1173-82.

38. Cohen J. Statistical power analysis for the behavioral sciences, 2nd edn. Hillsdale: Lawrence Erlbaum and Associates, 1988:567

39. Arnstein P, Caudill M, Mandle CL, Norris A, Beasley R. Self efficacy as a mediator of the relationship between pain intensity, disability and depression in chronic pain patients. Pain 1999;80:483-91.

40. Sullivan MJL, Stanish W, Sullivan ME, Tripp D. Differential predictors of pain and disability in patients with whiplash injuries. Pain Res Manag 2002;7:68-74.

41. Turk DC, Okifuji A, Scharff L. Chronic pain and depression: Role of perceived impact and perceived control in different age cohorts. Pain 1995;61:93-101. 
42. Paykel ES, Myers JK, Dienelt MN, Klerman GL, Lindenthal JJ, Pepper MP. Life events and depression. A controlled study. Arch Gen Psychiat 1969;21:753-60.

43. Kendler KS, Hettema JM, Butera F, Gardner CO, Prescott CA. Life event dimensions of loss, humiliation, entrapment, and danger in the prediction of onsets of major depression and generalized anxiety. Arch Gen Psychiat 2003;60:789-96.

44. Finlay-Jones R, Brown GW. Types of stressful life event and the onset of anxiety and depressive disorders. Psychol Med 1981;11:803-15.

45. Montada L. Attribution of responsibility for losses and perceived injustice. In: Montada L, Sigrun-Heide F, Lerner MJ, eds. Life Crises and Experiences of Loss in Adulthood. Hillsdale: Lawrence Erlbaum and Associate, 1992:133-61.

46. Abramson LY, Alloy LB, Metalsky GI. Hopelessness depression - a theory-based subtype of depression. Psychol Rev 1989;96:358-72.

47. Beck AT, Weissman A, Lester D, Trexler L. The measurement of pessimism: The hopelessness scale. J Consult Clin Psychol 1974:42:861-5.

48. Peterson C, Seligman MEP. Learned helplessness and victimization. J Soc Issues 1983;39:103-16.

49. Swallow SR, Kuiper NA. Social comparison and negative selfevaluations: An application to depression. Clin Psychol Rev 1988;8:55-76.

50. Bäzner E, Brömer P, Hammelstein P, Meyer TD. Current and former depression and their relationship to the effects of social comparison processes. Results of an internet based study. J Affect Disord 2006;93:97-103.

51. Sullivan MJL, Thorn B, Haythornthwaite JA, et al. Theoretical perspectives on the relation between catastrophizing and pain. Clin J Pain 2001;17:52-64.

52. Sullivan MJL, Stanish W, Waite H, Sullivan M, Tripp DA. Catastrophizing, pain, and disability in patients with soft-tissue injuries. Pain 1998;77:253-60.

53. Boothby JL, Thorn BE, Overduin LY, Ward LC. Catastrophizing and perceived partner responses to pain. Pain 2004;109:500-6

54. Ferguson T, Rule B. An attributional perspective on anger and aggression. In: Geen R, Donnerstein E, eds. Aggression: Theoretical and empirical reviews. New York: Academic Press, 1983:41-74.

55. Mikula G, Scherer KR, Athenstaedt U. The role of injustice in the elicitation of differential emotional reactions. Pers Soc Psychol Bull 1998;24:769-83.

56. Hardy JD, Smith TW. Cynical hostility and vulnerability to disease: Social support, life stress, and physiological response to conflict. Health Psychol 1988;7:447-59.

57. Zautra AJ, Burleson MH, Matt KS, Roth S, Burrows L. Interpersonal stress, depression, and disease activity in rheumatoid arthritis and osteoarthritis patients. Health Psychol 1994;13:139-48.

58. Hammen C. Stress and depression. Annu Rev Clin Psychol 2005;1:293-319.

59. Revenson TA, Schiaffino KM, Majerovitz SD, Gibofsky A. Social support as a double-edged sword: The relation of positive and problematic support to depression among rheumatoid arthritis patients. Soc Sci Med 1991;33:807-13.
60. McParland JL, Eccleston C, Osborn M, Hezseltine L. It's not fair: An interpretative phenomenological analysis of discourses of justice and fairness in chronic pain. Health 2011;15:459-74.

61. DeGood DE, Kiernan B. Perception of fault in patients with chronic pain. Pain 1996;64:153-9.

62. Burns JW, Bruehl S. Anger management style, opioid analgesic use, and chronic pain severity: A test of the opioid-deficit hypothesis. J Behav Med 2005;28:555-63.

63. Fernandez E, Turk DC. The scope and significance of anger in the experience of chronic pain. Pain 1995;61:165-75.

64. Brody CL, Haaga DAF, Kirk L, Solomon A. Experiences of anger in people who have recovered from depression and never-depressed people. J Nerv Ment Dis 1999;187:400-5.

65. Jack DC, Dill D. The silencing the self scale: Schemas of intimacy associated with depression in women. Psychol Women Quart 1992;16:97-106.

66. Burns JW. Anger management style and hostility: Predicting symptom-specific physiological reactivity among chronic low back pain patients. J Behav Med 1997;20:505-22.

67. Bruehl S, Chung OY, Burns JW, Biridepalli S. The association between anger expression and chronic pain intensity: Evidence for partial mediation by endogenous opioid dysfunction. Pain 2003;106:317-24.

68. McParland JL, Knussen C. Just world beliefs moderate the relationship of pain intensity and disability with psychological distress in chronic pain support group members. Eur J Pain 2010;14:71-6.

69. Montada L, Lerner MJ. Individual differences in the belief in a just world and responses to personal misfortune. In: Montada L, Lerner MJ, eds. Responses to victimizations and belief in a just world. New York: Plenum Press, 1998:65-86.

70. Festinger L. A theory of cognitive dissonance. Stanford: Stanford Univ Press, 1957.

71. Deffenbacher JL. Cognitive-behavioral conceptualization and treatment of anger. J Clin Psychol 1999;55:295-309.

72. Hayes SC, Luoma JB, Bond FW, Masuda A, Lillis J. Acceptance and commitment therapy: Model, processes and outcomes. Behav Res Ther 2006;44:1-25.

73. McCracken LA, Eccleston C. Coping or acceptance: What to do about chronic pain? Pain 2003;105:197-204.

74. Graham JE, Lobel M, Glass P, Lokshina I. Effects of written anger expression in chronic pain patients: Making meaning from pain. J Behav Med 2008;31:201-12.

75. D'Souza R, Rodrigo A. Spiritually augmented cognitive behavioural therapy. Australas Psychiatry. 2004;12:148-52.

76. Drwecki B, Moore C, Ward S, Prkachin K. Reducing racial disparities in pain treatment: The role of empathy and perspectivetaking. Pain 2011;152:1001-6.

77. De Vogli R, Ferrie JE, Chandala T, Kivimaki M, Marmot MG. Unfairness and health: Evidence from the Whitehall II study. J Epidem Comm Health 2007;61:513-8. 


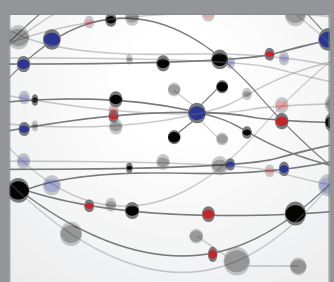

The Scientific World Journal
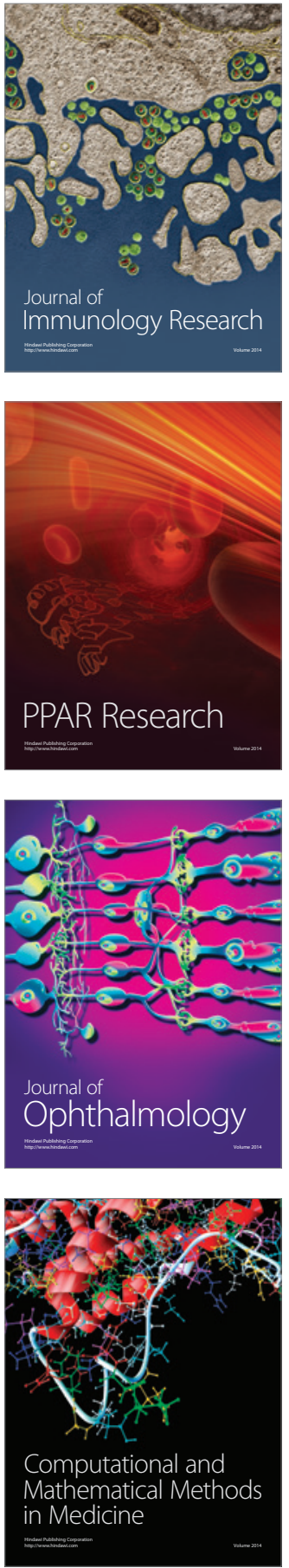

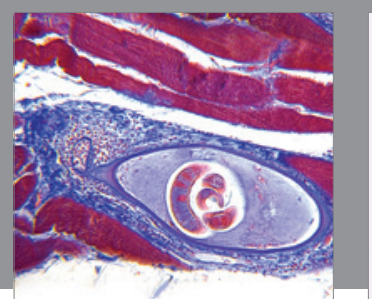

Gastroenterology Research and Practice

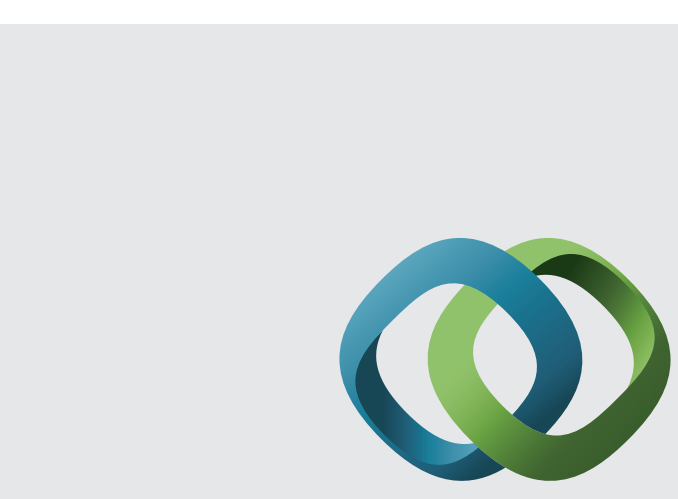

\section{Hindawi}

Submit your manuscripts at

http://www.hindawi.com
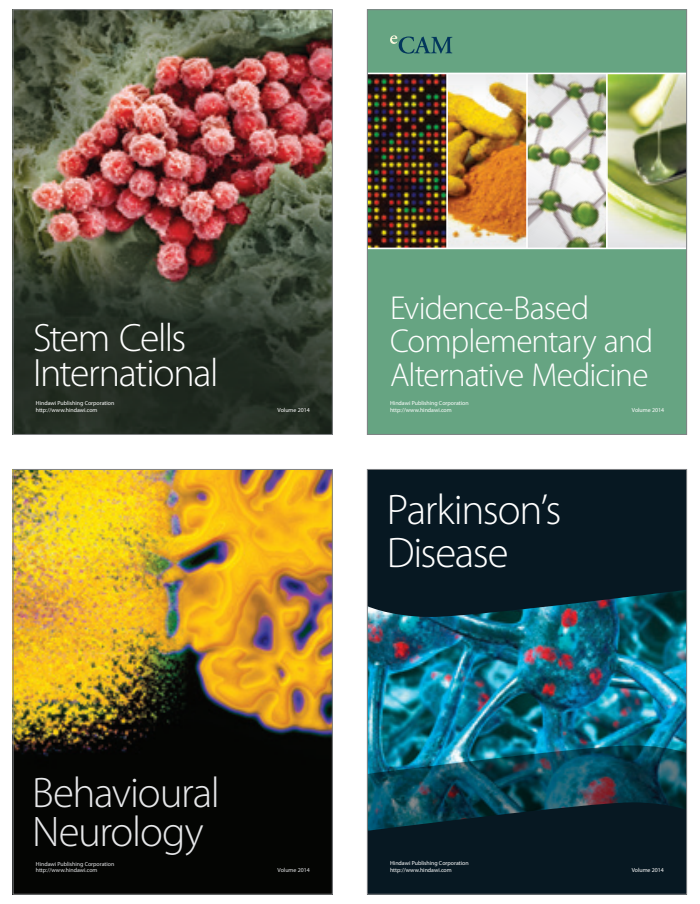
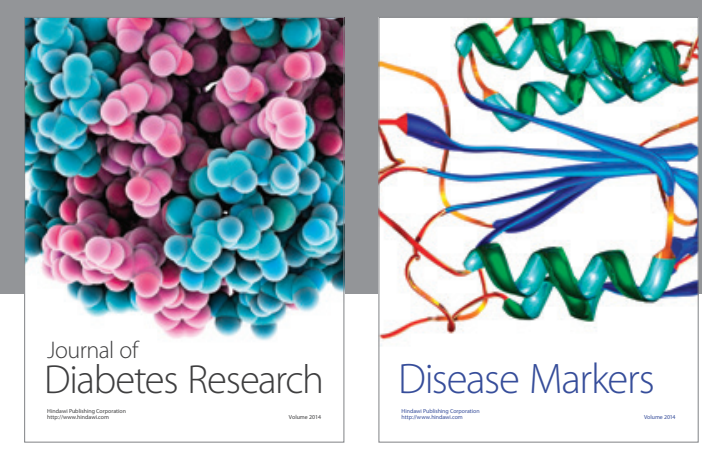

Disease Markers
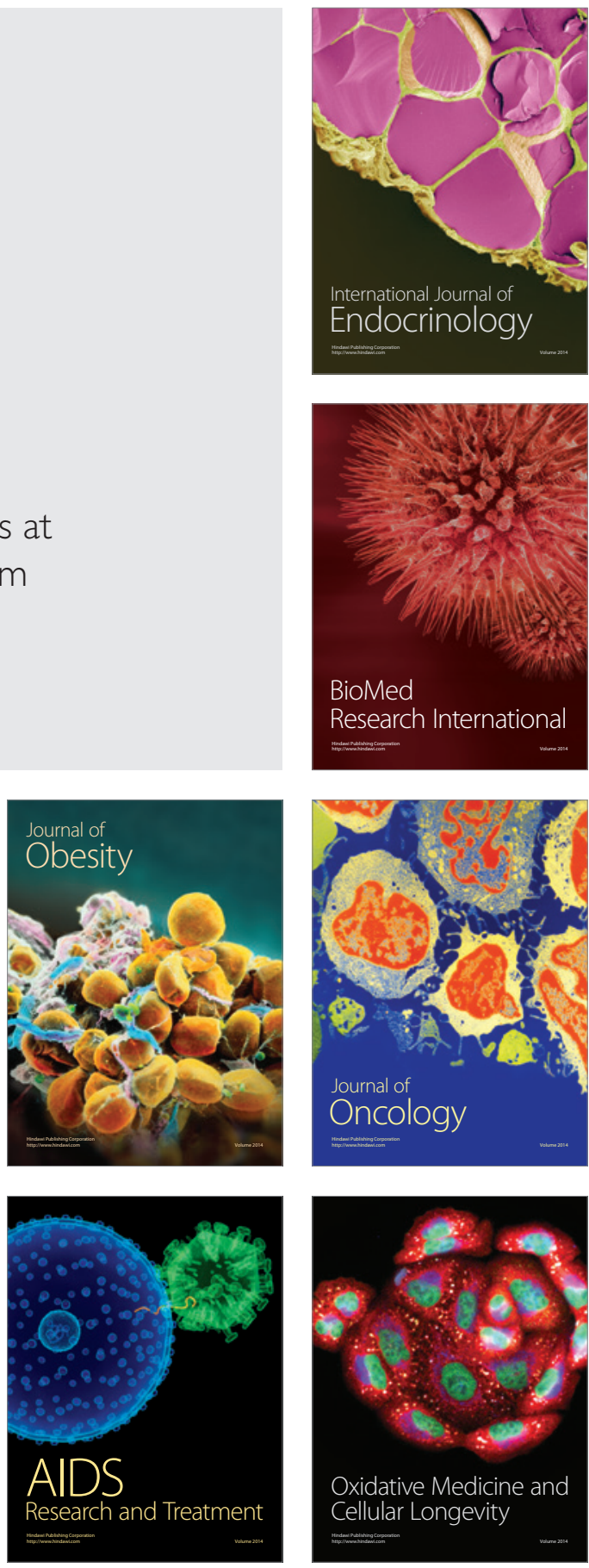